F.A.O.: Second Committee on Calorie Requirements (1957). F.A.O. nutr. Stud. no. I5.

Ganzin, M. J. (1954). In Malnutrition in African Mothers, Infants and Young Children. Report of the Second Inter-African (CCTA) Conference on Nutrition, Gambia, I952, p. 200. [B. S. Platt, editor.] London: H.M. Stationery Office.

Holmes, E. G., Stanier, M. W., Semambo, Y. B. \& Jones, E. R. (195 I). Trans. R. Soc. trop. Med. Hyg. 45, 37I.

Hytten, F. E. \& Duncan, D. L. (1956). Nutr. Abstr. Rev. 26, 855.

King, E. J. (195I). Micro-analysis in Medical Biochemistry, and ed. London: J. and A. Churchill.

Leung, W. W., Pecot, R. K. \& Watt, B. K. (1952). Agric. Handb. U.S. Dep. Agric. no. 34.

Nicol, B. M. (1956). W. Afr. med. F. 5, 157.

Nicol, B. M. (1959). Brit. F. Nutr. 13, 293.

Orr, M. L. \& Watt, B. K. (1957). Home Econ. Res. Rep. U.S. Dep. Agric. no. 4.

Pett, L. B. (1955). Amer. F. publ. Hlth, 45, 862.

Phillips, R. A., Van Slyke, D. D., Hamilton, P. B., Dole, V. P., Emerson, K. Jr. \& Archibald, R. M. (1950). F. biol. Chem. 183, 305.

Platt, B. S. (1945). Spec. Rep. Ser. med. Res. Coun., Lond., no. 253.

Platt, B. S. (1958). Proc. Nutr. Soc. 17, xl.

Rao, M. V. R. (1954). In Malnutrition in African Mothers, Infants and Young Children. Report of the Second Inter-African (CCTA) Conference on Nutrition, Gambia, 1952, p. 358. [B. S. Platt, editor.] London: H.M. Stationery Office.

Raoult, A. (1954). In Malnutrition in African Mothers, Infants and Young Children. Report of the Second Inter-African (CCTA) Conference on Nutrition, Gambia, 1952, p. 37. [B. S. Platt, editor.] London: H.M. Stationery Office.

Stanier, M. W. \& Holmes, E. G. (1954). Brit. F. Nutr. 8, 155 .

Sunderman, F. W. \& Boerner, F. (1949). Normal Values in Clinical Medicine. Philadelphia and London: W. B. Saunders Co.

Van Slyke, D. D., Phillips, R. A., Dole, V. P., Hamilton, P. B., Archibald, R. M. \& Plazin, J. (I950). 7. biol. Chem. $\mathbf{1 8 3}, 349$.

Waterlow, J. C. (editor) (1955). Protein Malnutrition: Proceedings of a Conference in Famaica, 1953. Rome: FAO/WHO/Josiah Macy Jr. Foundation.

Woodruff, A. W. (1951). Brit. med. F. ii, 14I5.

Woodruff, A. W. (1955). Brit. med. F. i, 1297.

\title{
The determination of body composition of living animals
}

\section{The daily endogenous creatinine excretion as a measure of body composition in rats}

\author{
BY I. KUMAR,* D. G. LAND† AND A. W. BOYNE \\ Rowett Research Institute, Bucksburn, Aberdeen
}

(Received 5 December I958-Revised I3 April 1959)

In many nutritional and metabolic experiments it is desirable to know the mass of one or both of the main components of the animal body, namely storage, or non-essential, fat and lean body mass (L.B.M.) (Behnke, I94I-2). These components, together with the gut contents, make up the live weight of the animal. Fat is the most variable of the three, and in many nutritional and dietary experiments its size is important. However, as it is not an actively metabolizing tissue, for some purposes it is often sufficient to know the size of the L.B.M. only. The constancy of the composition of the L.B.M. is

\footnotetext{
* Present address: Department of Animal Nutrition, Postgraduate College of Animal Sciences, Izatnagar (U.P.), India.

$\uparrow$ Present address: Ministry of Agriculture, Fisheries and Food, Experimental Establishment, Greyhope Road, Aberdeen.
} 
striking (Murray, I922; Moulton, I923; Pace \& Rathbun, I945). The gut contents, which may form a large part of the live weight, especially in herbivores, cannot be considered as a part of the animal body, but at times it may be necessary to know their mass in order to obtain the mass of one of the other components. This series of studies is concerned with the development and evaluation of methods for determining the mass of these components in living animals.

Over 50 years ago Folin (1905) postulated that the daily creatinine excretion, which he showed to be fairly constant for a given adult individual, was related to the muscle mass, or to the active protoplasmic mass, of the body. Since then many attempts have been made to utilize this postulate in estimating the various body components in man and other animals. Although the evidence available suggests that creatinine excretion and some body components are correlated, nowhere do the correlations appear to be close enough to provide accurate predictions of any of these components. Beard (1943), in the latest review, has strongly criticized Folin's idea and denied the usefulness of creatinine excretion for estimating the size of a major body component.

Folin's work led to the introduction, by Shaffer (1908), of the term 'creatinine coefficient' for the number of $\mathrm{mg}$ creatinine nitrogen excreted daily per $\mathrm{kg}$ bodyweight. McClugage, Booth \& Evans (I93I) reported on five very obese human subjects with a mean creatinine coefficient of $8 \cdot 25$, four normal subjects with a mean coefficient of $20^{\circ} 4$ and five subnormally developed subjects with a mean coefficient of 15.9. As the obese subjects lost weight, presumably fat, their creatinine excretion remained constant and the coefficient increased. These observations indicate an association between the creatinine coefficient and the proportion of muscle in the body. Similar results were obtained by Talbot (1938) in obese, normal, lean but muscular, and emaciated children. Recently, Muldowney, Crooks \& Bluhm (1957) have obtained a correlation $(r=0.73)$ between daily creatinine excretion and L.B.M. as estimated by antipyrine. Ryan, Williams, Ansell \& Bernstein (1957) have obtained in fourteen normal and twelve diseased subjects the relationship

$$
\text { C.M. }=14 \cdot 5+9 \cdot 5 C,
$$

where c.M. represents cell mass $(\mathrm{kg}), C$ creatinine excreted $(\mathrm{g} /$ day) and the standard error of the regression coefficient is $\pm 5^{\circ} \mathrm{I}$. Miller \& Blyth (1952) observed that from their data on forty-three subjects the L.B.M., determined densiometrically, could be predicted from the daily creatinine excretion to within $\pm 13.1 \%$ in $90 \%$ of the subjects $( \pm 15.7 \%$ in $95 \%$ of the subjects). Correlations have also been obtained with L.B.M. determined by skinfold thickness by Best (1953) $(r=0.643)$ and Best, Kuhl \& Consolazio (1953) $(r=0.610)$. Garn \& Clark (1955) have shown a low, but significant, negative correlation $(r=-0.40)$ between creatinine coefficient and percentage fat in man obtained fromX-ray measurements of fat thickness in the mid-trochanteric region. Beard (1932), however, using the data of 400 ist-year medical students who analysed their own single $24 \mathrm{~h}$ samples of urine, found poor correlation with body-weight $(r=0.13)$ and the two-thirds power of body-weight $(r=0.13)$.

The only recent work with animals was done by Lofgreen \& Garrett (1954), who 
showed a correlation $(r=0.67)$ between the creatinine coefficient and the percentage of separable lean meat in steer carcasses, and by Beard \& Pizzolato (1945) who found that in rats the correlations between daily creatinine excretion and body-weight $(r=0.06)$ and between daily creatinine excretion and muscle weight $(r=0 \cdot 18)$ were not significant. In the work of the latter authors, although a large number of rats was used ( $(45)$, collections of urine were over 2 days only and no correction was made for dietary creatinine. They thus failed to eliminate at least two of the causes which we believe to be largely responsible for the general lack of precision in investigations of the relationships between creatinine excretion and the mass of body components. These causes are: ( $\mathrm{r}$ ) failure to correct for dietary creatinine; (2) day-to-day variation in total creatinine excretion, which could lead to large errors over the short collection period used by many workers; (3) errors in measuring the mass of a body component. These causes have been considered in the work reported here, the objects of which were: (a) to investigate how the endogenous creatinine excretion is related to the fatfree mass (F.F.M.), which is the nearest approach to the L.B.M. capable of being measured with any accuracy by the direct methods of carcass analysis (F.F.M. consists of L.B.M. less the mass of essential and structural lipid extracted with diethyl ether); and $(b)$ to investigate whether measurements that can be made in vivo can be used effectively for the prediction of F.F.M., total fat, nitrogen and water in the rat.

\section{EXPERIMENTAL}

Rats and their treatment. Hooded Lister rats, ranging in age from 60 to 146 days, were placed in individual Hopkins metabolism cages. Funnels and separators were washed down between 9.50 and 10.10 a.m. daily, the flask and beaker being replaced by fresh ones. Immediately afterwards the rats and food residues were weighed, and weighed amounts of fresh food given. The composition of the diet low in creatinine, offered $a d l i b$, is given in Table $\mathrm{I}$.

Table $\mathrm{I}$. Percentage composition of the low-creatinine diet

$\begin{array}{lr}\text { Whole-wheat flour } & 55 \\ \text { Ground maize } & 25 \\ \text { Wheat germ } & \text { Io } \\ \text { Dried yeast } & 4 \\ \text { Arachis oil } & 4 \\ \text { Salt mixture* } & 2 \\ \text { Crude protein } & \text { I4. I }\end{array}$

* McCollum's no. 185 containing $3.2 \%$ ferric citrate (British Drug Houses Ltd).

The pre-experimental period consisted of 7 days in which the rats were accustomed to the diet, cages, weighing and washing-down procedure. It was followed by a Ioday collection period. As some of the rats were used for an additional independent measure of body fat on either the Ist or the and day after the end of the collection period, all were killed with chloroform on the $3^{\text {rd day. }}$

Each rat was weighed, cooled to room temperature and opened, and the gut contents were rapidly removed. The empty intestines were replaced and the cleaned 
carcass was weighed. It was then rapidly minced and its water content determined by freeze-drying, which reduced the moisture content to less than $\mathrm{r} \%$. The dry material, which was hygroscopic, was reduced to a powder by means of a small household mincer and analysed for nitrogen (macro-Kjeldahl), ether extract and moisture (oven drying at $\left(100^{\circ}\right)$. F.F.M. was obtained by subtraction of the weight of fat from the cleaned carcass weight.

Measurement of creatinine. The urine was filtered, the residue washed and pooled filtrate and washings were made up to a volume of 100 or $25^{\circ} \mathrm{ml}$. Samples were taken for duplicate creatinine analyses by the method of Owen, Iggo, Scandrett \& Stewart (1954), but with fuller's earth (British Drug Houses Ltd, for adsorptive purposes) in place of Lloyd's reagent and with the picrate solutions kept away from bright light. This method removes almost all non-creatinine chromogen. The optical densities of the solutions at $520 \mathrm{~m} \mu$ were measured in $10 \mathrm{~mm}$ cells in a Beckmann DU spectrophotometer, while the temperature was controlled at $20^{\circ}$. Duplicate measurements were done on samples, on standard creatinine solutions containing $\mathrm{I}_{5}$ and $30 \mu \mathrm{g} / \mathrm{ml}$ and on a blank, the optical densities being read against water. As Beer's law is valid over only a restricted range of creatinine concentration, the volume of diluted urine used was chosen to contain between 15 and $30 \mu \mathrm{g}$ creatinine. If the creatinine concentration was outside this range the analysis was repeated the following day with a more suitable volume of urine. The urine was usually analysed on the day of collection; if not it was stored at $\mathrm{I}^{\circ}$ until the next day. Under these storage conditions the change in creatinine concentration is negligible (Drabbe \& Reinhold, 1952). The picric acid used satisfied the criteria of purity of Folin \& Doisy (1917).

The diet was exhaustively extracted with water and the creatinine content of the extract determined. It was found to contain $4 \mathrm{I} \mu \mathrm{g}$ creatinine/g and the daily intake of creatinine was calculated from the food intake and subtracted from the total urinary creatinine to give the endogenous value. This correction was based on the assumption that dietary creatinine is completely absorbed and excreted quantitatively in the urine. As the maximum dietary creatinine intake was $\mathrm{I} \mathrm{mg}$ and as the lowest recoveries of repeated daily oral doses of creatinine reported are about $80 \%$ (Hunter, 1928), the largest error likely to arise from this source was $0 \cdot 2 \mathrm{mg}$. This value represented about $2 \%$ of the daily endogenous excretion and was of little importance under the conditions of our experiment.

Body-weight. The mean body-weight of a rat during the ro-day collection period was calculated from the weights obtained daily. From it the weight of gut contents at the end of the experiment was subtracted to give the mean cleaned weight. The carcass composition at the middle of the collection period was calculated on the assumption that it was the same as at slaughter.

Design of the experiment. Preliminary work on female rats had indicated that creatinine excretion over an extended period varied with body composition. To investigate the relationship further, five litters of six male rats and five litters of six female rats were used in the experiment reported in this paper. The rats were all above the age of puberty (5o days), because creatinine excretion is reported to increase up to, and to be constant beyond, this age (Hunter, 1928). 
The diet was chosen to contain very little creatinine in order to reduce the dietary correction and thus minimize dietary errors in the endogenous value.

Choice of the length of the collection period was difficult. For convenience it should be as short as possible; in preliminary work considerable day-to-day fluctuation in endogenous creatinine excretion was found (Fig. I), which would make a long collection period desirable. As a compromise a ro-day collection period was chosen.

\section{RESULTS AND DISCUSSION}

The values for daily endogenous creatinine excretion and body composition are summarized in Table 2. The within-litter standard deviations show that in certain measures males were more variable than females. However, when regression analyses were made the residual variability was similar for both sexes. There was a wide variation in body-weight and F.F.M. within litters, as shown by the within-litter standard deviations. Comparison of the litter means for these values with the age of each litter indicates that much of the variability in body-weight and F.F.M. between litters was associated with differences in age.

Table 2. Mean values for endogenous creatinine excretion and body composition of litters of six rats

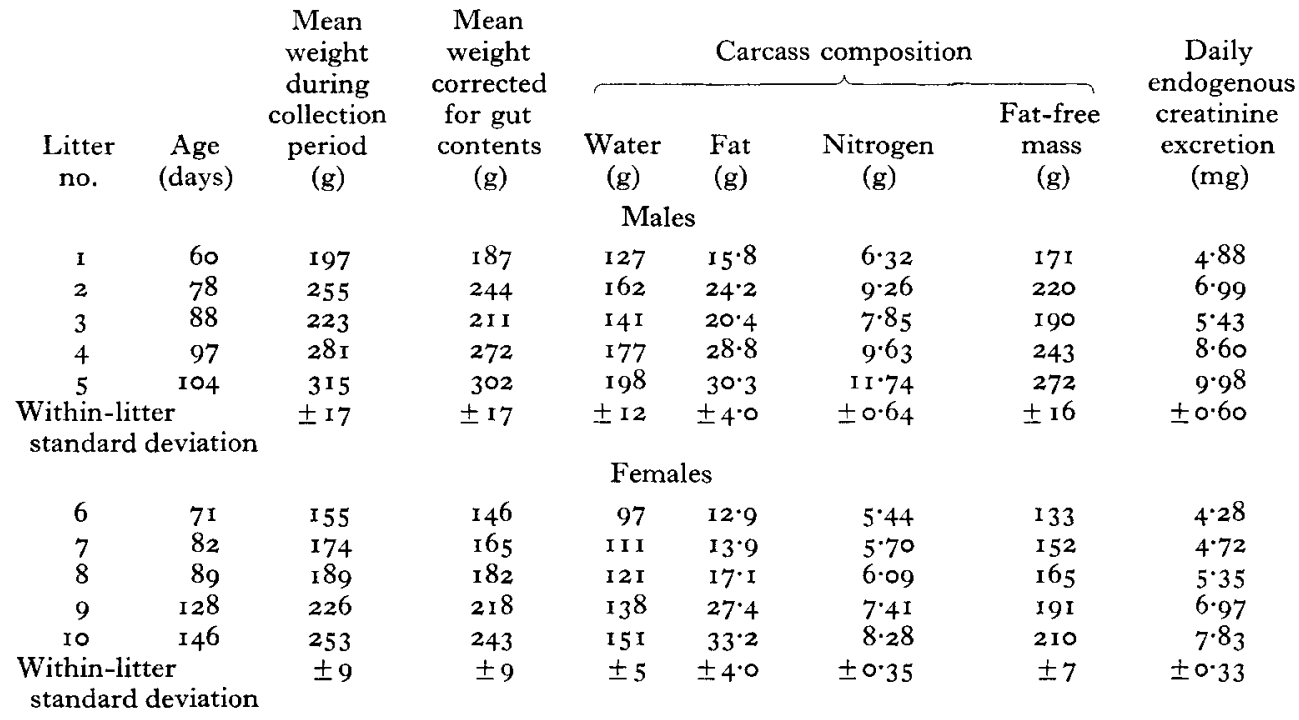

\section{Influence of fat-free mass on daily endogenous creatinine excretion}

The same relationship held within all ten litters, a difference between litter-mates of $+\mathrm{I} g$ in F.F.M. being associated on average with a difference of $+0.0345 \pm 0.0027 \mathrm{mg}$ in daily endogenous creatinine excretion. This relationship did not hold between litters. When litter means were examined it was found that a difference of $+\mathrm{I} g$ in F.F.M. between unrelated rats of the same sex resulted on average in a difference of $+0.0515 \pm 0.0024 \mathrm{mg}$ in daily creatinine excretion. This relationship is illustrated in 
Fig. $x$ by the marked increase in endogenous creatinine excretion by four of the rats during the collection period, compared with the other two which showed no overall increase. These two rats were of almost constant weight over the period whereas the other four were increasing in weight, the increase being largely a reflection of increases in F.F.M. There was a sex difference in the level of creatinine excretion $(P<0.00 \mathrm{I})$, in

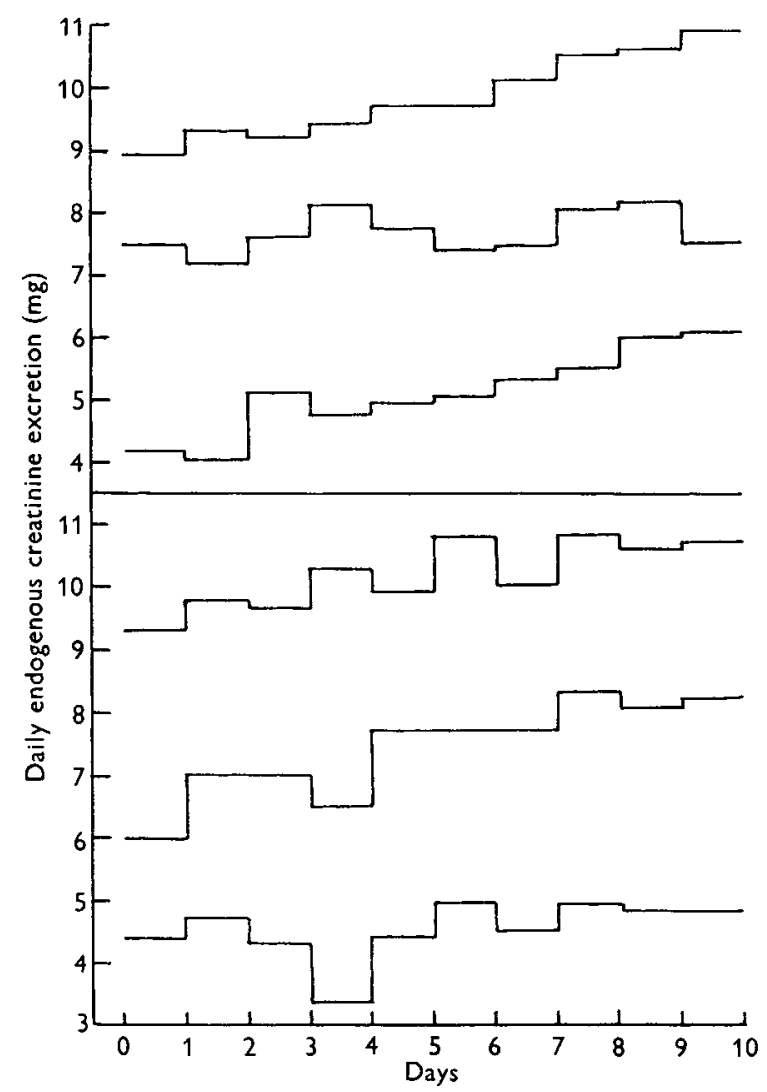

Fig. I. Some patterns of daily endogenous creatinine excretion by rats.

that a female with a given F.F.M. excreted I.20 mg more endogenous creatinine daily than a male with the same F.F.M. The equations were:

Males: creatinine excretion $(\mathrm{mg})=0.0515$ F.F.M. $(\mathrm{g})-4 \cdot 12$,

Females: creatinine excretion $(\mathrm{mg})=0.05 \mathrm{I} 5$ F.F.M. $(\mathrm{g})-2.92$.

This sex difference is also illustrated in Fig. 2, in which the daily endogenous creatinine excretion is plotted against F.F.M.

The apparent additional effect of F.F.M. between litters compared with its effect within litters may have been associated with differences in age between litters, greater age and greater F.F.M. both contributing to increase in endogenous creatinine excretion. These results do not support Hunter's (1928) conclusion that creatinine excretion 
does not increase after puberty, although there is some evidence that the rate of increase with age becomes slower.

It is also apparent from the sex difference noted above that the use of the ratio of creatinine excretion to F.F.M. is by itself inadequate to describe how the two measures are related to one another.

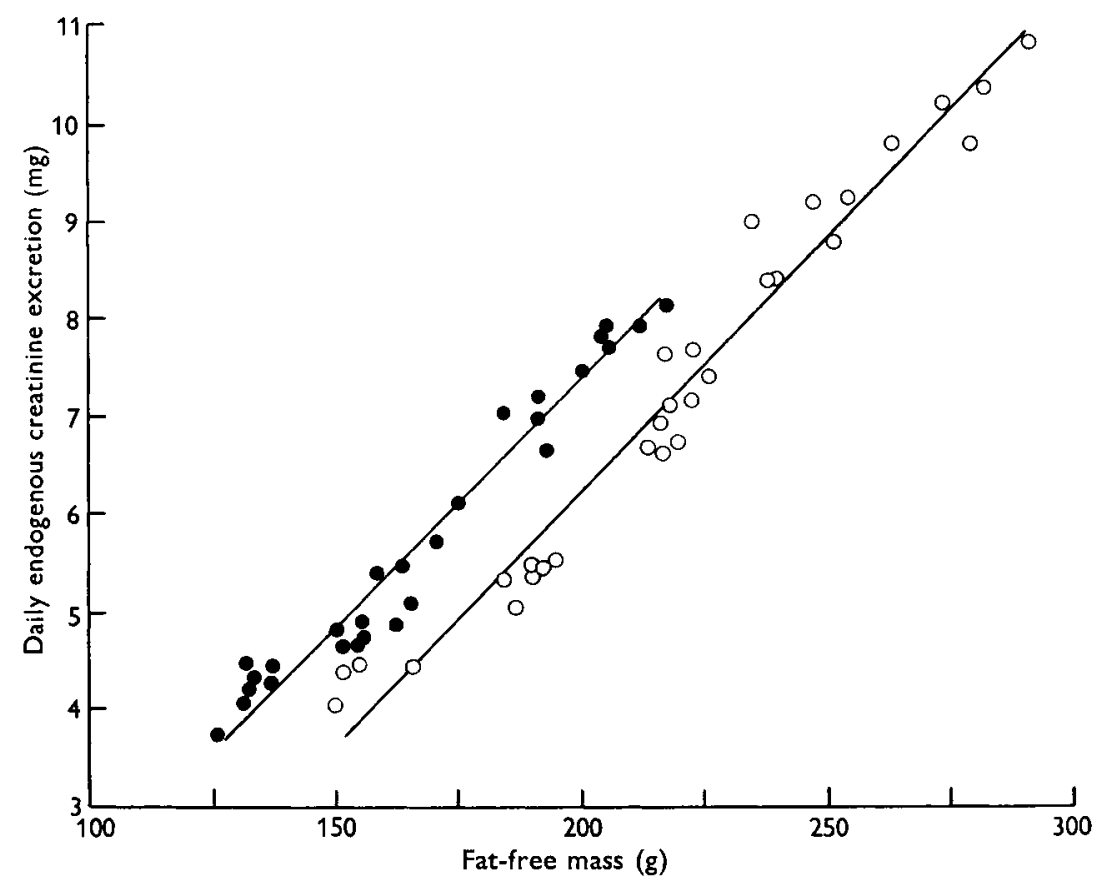

Fig. 2. Relationship between daily endogenous creatinine excretion and fat-free mass of rats. $\bigcirc$, males; -, females. Males: $y=0.0515 x-4 \cdot 12$; females: $y=0.0515 x-2 \cdot 92$.

Factors, measurable in vivo, entering into the prediction of the content of fat-free mass, fat, nitrogen and water from the endogenous creatinine excretion in the rat

The measurements that could reasonably be made on the live animal were of live weight, creatinine excretion, age, and weight change. Their bearing on the body measurements obtained by carcass analysis was examined for males and females separately. Weight change did not contribute information on any measurement and no reference is made to it in the results and discussion below.

\section{Males}

Fat-free mass. The within-litter regression on daily endogenous creatinine excretion and live weight was similar for each litter and the values could be combined to give a pooled within-litter regression coefficient. Differences between litters were no greater than would be expected from the within-litter variability and so it was possible to give an overall equation:

$$
\text { F.F.M. }(\mathrm{g})=0.68 \times \text { live weight }(\mathrm{g})+4.40 \times \text { creatinine }(\mathrm{mg} / \text { day })+\mathrm{I} 3 \cdot 9 .
$$


The standard errors of the regression coefficients were \pm 0.08 and $\pm \mathrm{I} .8$ respectively, and the residual standard deviation was $\pm 3.8 \mathrm{~g}$ which was about $2 \%$ of the mean value. In this equation, although live weight gave more information than creatinine, both regression coefficients were significant. Inclusion of the creatinine term in the equation reduced unaccountable variation by a further $16 \%$ of its value if only live weight was included. This is likely to be a minimum figure as no attempt was made to obtain a wide range of body composition within litters in the present experiment. As all the rats were fed on the same diet there was little variation in body composition; live weight was more closely related to F.F.M. than would be expected under conditions in which a greater range of body composition was obtained. The absence of significant differences between litters implied that age differences between litters, apart from the effect of age as reflected in creatinine excretion and live weight, were not important in predicting F.F.M. over the range of values of this experiment.

Fat. The result of the analysis was similar to that for the prediction of F.F.M. and it was possible to give an overall equation:

$$
\text { Fat }(g)=0.24 \times \text { live weight }(g)-2.5 \mathrm{I} \times \text { creatinine }(\mathrm{mg} / \text { day })-\mathrm{I} 8.4 \text {. }
$$

The standard errors of the regression coefficients were \pm 0.07 and \pm 0.57 respectively, and the residual standard deviation was $\pm 3.3 \mathrm{~g}$. The similarity in residual standard deviations for the prediction equations for F.F.M. and fat is to be expected as errors in measuring one dependent variate are highly negatively correlated with errors in the other. However, the coefficient of variation for fat, about $14 \%$, represents a much greater proportionate error than for F.F.M.

Nitrogen and water. Within-litter regression coefficients for the prediction of body nitrogen and body water are given in Table 3 , together with those for F.F.M. and body fat. They show that measurements of both live weight and creatinine excretion contributed information on nitrogen and water content, but differences between litters were highly significant and were not associated with age, the only remaining measurement made on the live rats. It was therefore not possible to give overall prediction equations for body nitrogen and body water.

Table 3. Within-litter partial regression coefficients of carcass measures on $(a)$ daily endogenous creatinine excretion $(m g)$ and $(b)$ mean live weight $(g)$

$\quad$ Variable
Body fat $(\mathrm{g})$
Fat-free mass $(\mathrm{g})$
Body nitrogen $(\mathrm{g})$
Body water $(\mathrm{g})$

\begin{tabular}{cc}
\multicolumn{2}{c}{$a$} \\
Males
\end{tabular}

\begin{tabular}{ll}
\multicolumn{1}{c}{ Males } & \multicolumn{1}{c}{ Females } \\
$0.33 \pm 0.08$ & $0.34 \pm 0.08$ \\
$0.61 \pm 0.10$ & $0.63 \pm 0.10$ \\
$0.025 \pm 0.003$ & $0.035 \pm 0.005$ \\
$0.45 \pm 0.08$ & $0.47 \pm 0.06$
\end{tabular}

\section{Females}

Fat-free mass. The results were similar to those for the males, the within-litter regressions being consistent between litters. However, it was found that only live weight contributed a significant amount of information on this measure and when the regression on live weight had been taken into account, the residual standard 
deviation in F.F.M. was $\pm 3.5 \mathrm{~g}$. The failure of creatinine measurement to add to the information on F.F.M. may well have been caused by the smaller overall variation in this measure (see Table 2). The equation was:

$$
\text { F.F.M. }(g)=0.77 \text { live weight }(g)+16 \cdot 0 \text {. }
$$

Fat. The results were similar to those for F.F.M., only live weight contributing information.

The equation was: Fat $(\mathrm{g})=0.23$ live weight $(\mathrm{g})-25 \cdot 0$,

and the residual standard deviation $\pm 3.7 \mathrm{~g}$.

Nitrogen and water. Results similar to those for the males were again obtained, but as with F.F.M. and fat, measurement of creatinine excretion did not contribute any information not provided by that of live weight.

The failure of the creatinine measurement to add useful information on these four measures in females is indicated in Table 2 by the appropriate regression coefficients on creatinine excretion being less than twice their standard errors.

\section{Residual variability}

The residual variability in predicted F.F.M. and fat in both males and females was then further investigated in terms of the actual measures obtained by carcass analysis. It was found that the F.F.M. prediction equation underestimated F.F.M. in rats with a low fat content and overestimated it in those with a high fat content. The inverse relationship held between predicted fat content and that measured. One would normally expect the magnitude of errors in prediction of total fat to be associated with the weight of fat obtained by analysis in that the high values tend to be underestimated and the low values overestimated. In this instance, for male rats, the correlation coefficient between the errors in predicted and measured fat weight was -0.48 , whereas the coefficient between the errors in predicted weight of fat and measured fat content was -0.85 , showing a much closer correlation. Thus it would seem that for some reason the predicted fat content of a lean rat is overestimated by measurement of live weight and endogenous creatinine excretion and that of a fat rat underestimated.

It is worth recording at this stage that the errors in technique of measuring fat, and consequently F.F.M., by carcass analysis, corresponded to a standard deviation of about $\pm 0.2 \mathrm{~g}$. When it is compared with the residual standard deviations of a little over $\pm 3 \mathrm{~g}$ with the variability due to regressions eliminated, it can be seen that there is room for improvement in prediction.

The high correlation between the errors in the predicted fat content and the measured fat content suggests that it might well be worth while, with larger animals, to make some attempt to obtain supplementary information on fat content such as back-fat thickness in pigs, or some measure analogous to skinfold thickness in man. The possibility of combining this information with measures of endogenous creatinine excretion, live weight and age to improve the prediction of body fat and F.F.M. should be examined. It would be more important for fat than for F.F.M., for which a coefficient of variation of only $2 \%$ has been obtained. 


\section{SUMMARY}

I. The influence of fat-free body mass on the daily endogenous creatinine excretion and the measurements entering into the prediction of fat-free mass, fat, nitrogen and water content from the endogenous creatinine excretion were studied in five litters of six male and five litters of six female rats.

2. In both sexes the endogenous creatinine excretion increased with the size of the fat-free mass and also with age. Females of a given fat-free mass had a higher rate of endogenous creatinine excretion than males of the same fat-free mass.

3. In the males the following prediction equations were obtained:

Fat-free mass $(\mathrm{g})=0.68$ live weight $(\mathrm{g})+4.40$ creatinine $(\mathrm{mg} /$ day $)+\mathrm{r} 3.9$, residual standard deviation $\pm 3.8 \mathrm{~g}$.

Fat $(\mathrm{g})=0.24$ live weight $(\mathrm{g})-2.5 \mathrm{I}$ creatinine $(\mathrm{mg} /$ day $)-{ }_{\mathrm{I}} 8.4$, residual standard deviation $\pm 3 \cdot 3 \mathrm{~g}$.

It was not possible to produce equations predicting content of nitrogen or water.

4. For the females, creatinine excretion did not add information to that given by live weight.

5. The magnitude of errors in prediction of fat-free mass and fat was associated with the measured fat percentage. It is suggested that when larger animals, such as pigs, are examined, an attempt should be made to incorporate in the equation predicting body fat some supplementary measure of fat content, such as backfat thickness. The equation predicting fat-free mass has a coefficient of variation of $2 \%$, which is probably sufficiently accurate for most purposes.

The authors wish to thank Dr J. Duckworth for his advice and encouragement and also Mr W. S. Mackie and Mr R. I. Smart for technical assistance.

Beard, H. H. (1932). Hum. Biol. 4, 351 .

\section{REFERENCES}

Beard, H. H. (1943). Creatine and Creatinine Metabolism. New York: Chemical Publishing Co. Inc. Beard, H. H. \& Pizzolato, P. (1945). Exp. Med. Surg. 3, 344.

Behnke, A. R. (1941-2). Harvey Lect. 37, I98.

Best, W. R. (1953). U.S. Army Med. Nutr. Lab. Rep. no. I I8.

Best, W. R., Kuhl, J. \& Consolazio, C. F. (1953). Fed. Proc. 12, 178.

Drabbe, C. A. J. von F. \& Reinhold, J. G. (1952). F. Lab. clin. Med. 39, I63.

Folin, O. (1905). Amer. F. Physiol. 13, 66.

Folin, O. \& Doisy, E. A. (1917). F. biol. Chem. 28, 349 .

Garn, S. M. \& Clark, L. C. (1955). F. appl. Physiol. 8, I35.

Hunter, A. (1928). Creatine and Creatinine. London: Longmans, Green and Co. Ltd.

Lofgreen, G. P. \& Garrett, W. N. (1954). F. Anim. Sci. 13, 496.

McClugage, H. B., Booth, G. \& Evans, F. A. (193 I). Amer. F. med. Sci. 181, 349.

Miller, A. T. \& Blyth, C. S. (1952). F. appl. Physiol. 5, 73.

Moulton, C. R. (1923). F. biol. Chem. 57, 79.

Muldowney, F. P., Crooks, J. \& Bluhm, M. M. (1957). F. clin. Invest. 36, 1375.

Murray, J. A. (1922). F. agric. Sci. 12, 103.

Owen, J. A., Iggo, B., Scandrett, F. J. \& Stewart, C. P. (1954). Biochem. F. 58, 426.

Pace, N. \& Rathbun, E. N. (1945). F. biol. Chem. 158, 685.

Ryan, R. J., Williams, J. D., Ansell, B. M. \& Bernstein, L. M. (1957). Metabolism, 6, 365.

Shaffer, P. A. (1908). Amer. F. Physiol. 23, 1.

Talbot, N. B. (1938). Amer. F. Dis. Child. 55, 42. 